\title{
Denture labelling: An ID proof in dentistry
}

\author{
Archana Nagpal ${ }^{1, *}$, Puja $^{2}$, Anisha $^{3}$, Karan Duvedi ${ }^{4}$, Aayushi Singla ${ }^{5}$ \\ ${ }^{1}$ Professor and Head, ${ }^{2,3,4}$ Post Graduate Student, ${ }^{5}$ BDS Student, ${ }^{1-5}$ Dept. of Prosthodontics and Crown \& Bridge, Himachal Dental \\ College, Sunder Nagar, Himachal Pradesh, India
}

*Corresponding Author:

Email: archana.saidental@gmail.com

\begin{abstract}
Denture marking is now a universally undertaken means for identifying dentures and persons in geriatric institutions, during war, crimes, and civil unrest, natural and mass catastrophe, autopsy and medico-legal enquiry. This paper reviews the varied methods of denture labelling and its significance.
\end{abstract}

Keywords: Denture identification, Forensic odontology, Methods.

\section{Introduction}

There is increase in crime rate and its offenders, despite of the advancement in science. Therefore, the aim of Forensics is to act and perform deftly. According to American Board of Forensic Odontology Guidelines, most dental identifications are based on restorations, caries, missing teeth and/or prosthetic devices. In edentulous patients with high bone resorption, there are no consistent measures obtainable for comparison of ante mortem and post mortem picture taking analysis. ${ }^{1}$ In geriatric patients and in nursing homes, the need of labeling dentures increases drastically, wherever accidental exchange or loss of dentures is quite feasible. In addition to that, it aids in identification of patients tormented with severe physical and mental suffering and therefore saves the aged from difficulty in adjusting to new set of dentures. ${ }^{2}$ Therefore, patient's prosthesis; a dental plate that's tagged or labelled has the most effective likelihood for simple and easy identification. Due to the scarcity of comprehensive fingerprint information, dental identification is growing as an important part of rhetorical investigation. Prosthodontists have an important role to play in rhetorical odontology as they're involved with fabrication of varied prostheses which may act as a critical tool and means for identification. Thus, dental appliance marking is very important for the following: ${ }^{3}$

1. It helps in identification of an unknown denture wearer in cases involving cognitive state or senility, loss of memory, medical specialty cases, homicide, suicide, victims of fireside, explosion, floods, earthquake, plane crash, or war etc.

2. In lost and found cases, the dental appliance can be returned to the owner.

3. It is important than finger printing due to rapid and accurate technique.

4. Dental technicians can identify a dental appliance easily, particularly at the deflasking stage in laboratory, if it's marked / tagged.
5. To make sure the proper dental appliance delivery to the individual patient.

Historical Background: Teeth were used for identification of an individual from a very long time. Forensic odontology might have born at the Battle of Nancy in 1477, when the body of Charles the Bold was identified by the absence of a lower tooth. ${ }^{4}$ During the US Revolutionary War, Paul Reverse (1775), a young dental practitioner, identified war causalities by their bridgework. It is an ancient branch of forensic science which has been also defined by Keiser Nielsen (1970) as 'that branch of odontology which is concerned with the proper evaluation, interpretation and presentation of dental findings in the interests of justice'.

Dental identification is realistic practice under extreme circumstances, moreover since teeth are extraordinarily resistant to destruction and decomposition. It had been utilized in various numerous cases such as in case of Adolf Hitler and Eva Braun, the late Indian Prime Minister, Rajiv Gandhi and the late President of Pakistan, Zia-ul-Haq, in the New York City World Trade Center bombing, in the Waco Branch Davidien blockade, and infinite airplane crashes and natural catastrophe. ${ }^{3,6-11}$

\section{Criteria for Denture Labeling ${ }^{12}$}

1. The strength of the prosthesis should not be compromised.

2. It must be uncomplicated and cheap to apply.

3. The identification system must be efficient and economical.

4. The markings should be visible and durable.

5. The identification should tolerate humidness and fire.

6. The identification mark should be esthetically acceptable.

7. The identification mark should be biologically inert (when incorporated into the denture).

8. The marking ought to be permanent and resistant to everyday cleansing and disinfecting agents. 


\section{Methods of Denture Marking}

Denture labelling can be broadly classified into either ${ }^{13}$

1. Surface marking method

2. Inclusion method

\section{Surface Methods}

Scribing or Engraving the Denture: Two letters, that is initial letter of the name and of the cognomen, can be engraved with a small round dental bur on the fitting surface of the maxillary complete denture, which resulted in countersunk letters. Most typical area is distobuccal flange of maxillary and mandibular denture. ${ }^{13}$

Advantages: It is the simplest way of marking dentures.

Disadvantages: Initials of name do not provide much information and may be confusing.

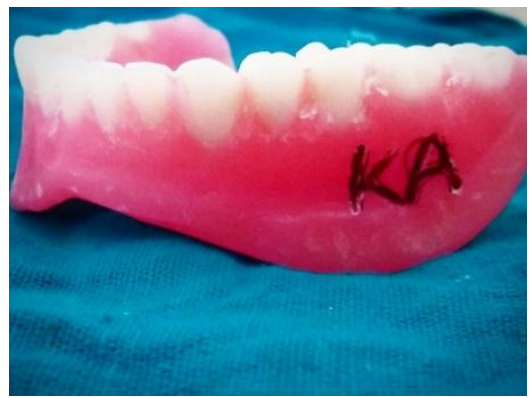

Fig. 1: Engraved denture

\section{Inclusion Method}

Metal Identification Bands: Dentures have been marked in Sweden with a stainless-steel metal band incorporated into the acrylic, containing the personal ID of the patient and incorporated to dental plate post or prefabrication. The Swedish ID-Band is currently the international customary among ID bands.

Advantages: It is resistant to very high temperatures, up to $1100^{\circ} \mathrm{C}$.

1. It is cheap

2. Requires no special instrumentation.

3. Radio-opaque

4. Esthetically acceptable.

Disadvantages: Metal insert will cause weakening of the dental plate at the point of insertion. ${ }^{14}$

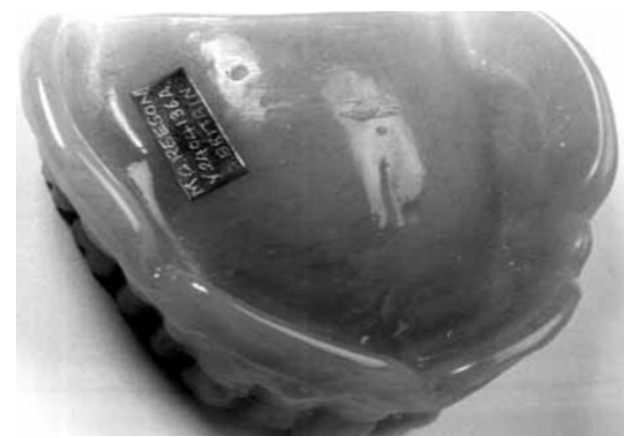

Fig. 2: Metal ID band denture
Computer-printed Denture Microlabeling System: Berry et al (1995) suggested a post fabrication technique for identification of prosthetic devices. The identification label bearing the patient's details was computer generated and placed in slot in the denture followed by saturated clear organic polymer applied to seal it $\&$ cured in an exceedingly pressure pot. ${ }^{15}$

Similarly Ling (1998) suggested a computerprinted denture microlabelling system in which Patient's details was computer written\& then photocopied onto a transparency sheet in 50\% reduced size. Once treating with cyanoacrylate acid esters adhesive solution the microlabel was then incorporated into the denture during the packing stage. ${ }^{16,17}$

Advantages: Can be done after fabrication of denture. Disadvantages: esthetically not much suitable.

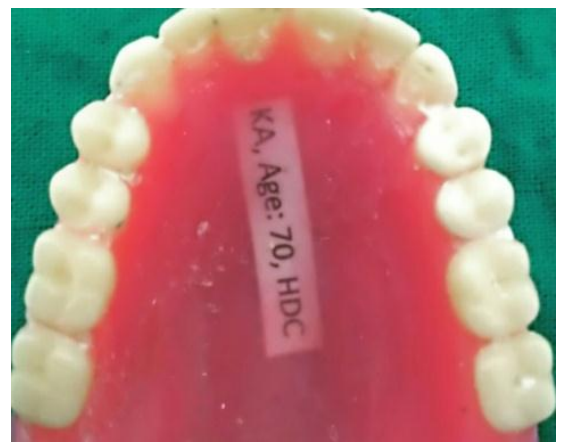

Fig. 3: Denture with computer labelling

Writing on the Denture: In this technique, patient's identification details are written on the tissue-fitting surface of the finished dental plate with a fiber-tip pen. The mark is best protected against abrasion by a minimum of two layers of varnish. ${ }^{18}$

Advantages: Easy to work with.

Disadvantages: It does not provide much information.

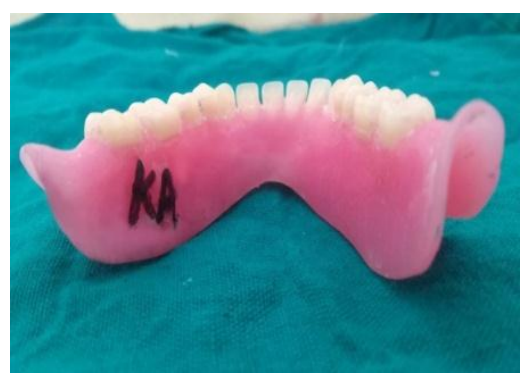

Fig. 4: Writing on the denture with fiber-tip pen

Lead Paper Label and Radiograph: Mona Sayed et al (2009) explained employing a lead foil paper found within the intra-oral photographic film to type the patient's information with any manual ribbon typewriter.

Advantages: This technique can be used during fabrication or after fabrication.

1. Lead foil is radio-opaque when it is subjected to another IOPA, details are projected on IOPA film. 
2. It is helpful in locating an aspirated temporary partial denture. ${ }^{19}$

Disadvantages: It is complicated than previous techniques.

Radiograph is required as reading directly from lead foil is not easy.

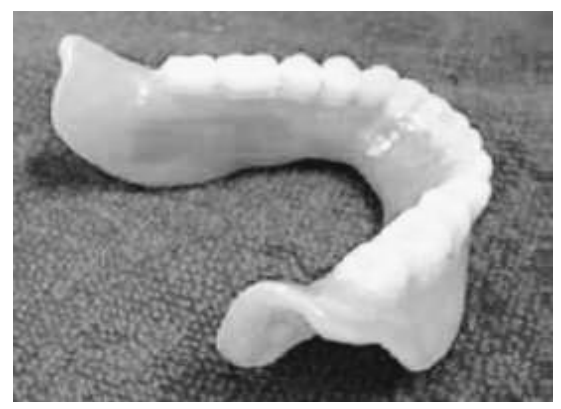

Fig. 5: Lead foil in denture

\section{Denture Bar Code/quick Review}

Code (QRC): Rajendran et al in 2012 devised a relatively simple 2-D bar-code technique with patient's details such as name, and social security number employing a code generator.

In this technique with the assistance of bar code generating software which is available free of cost, a patient specific bar code with all patient details is fabricated and printed. This is often then covered with transparent adhesive tape or transparent sheet and inserted into denture and covered with clear acrylic and finished, polished. To decipher it, hold a code decoderenabled mobile camera and is translated into text on the mobile phone display easily. ${ }^{20}$

Advantages: It is the latest and advanced method.

1. It is easy and cheap to generate.

2. Full patient information can be uploaded.

Disadvantages: If not fabricated properly, scanning is not possible.

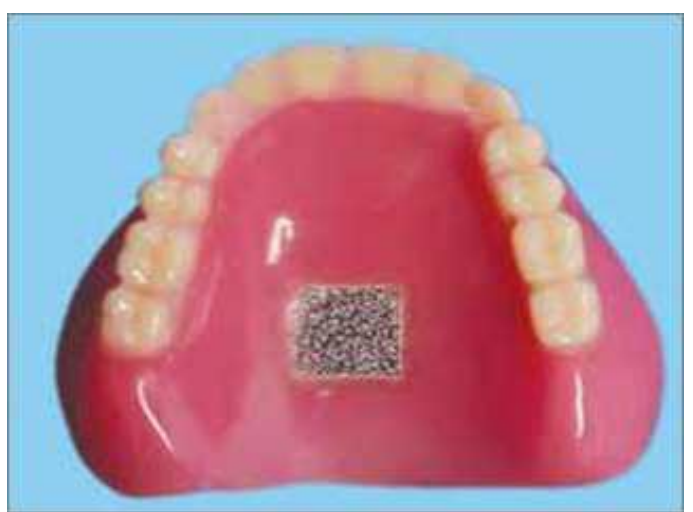

Fig. 6: Denture bar code

Photographic Method: In this methodology, patient's photograph is embedded within the dental plate with the help of clear acrylic resin
Advantages: This method is especially useful in the countries with low literacy rate where a photograph is the easiest way of identification.

1. It is also helpful in countries with diverse scripts.

Disadvantages: It cannot be used in burn case victims or severe face injury cases.

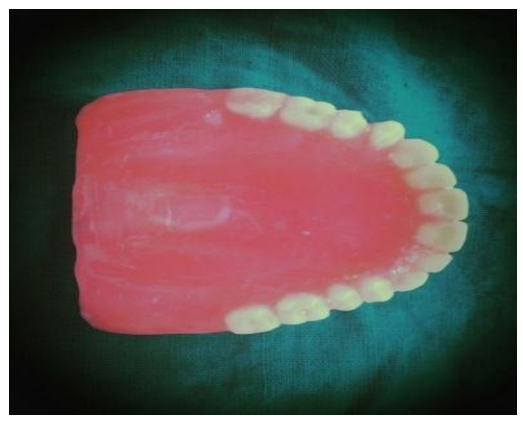

Fig. 7: Denture with photograph

Lenticular System: Lenticular printing introduced by Colvenkar in 2010, in which a convexo-convex lens is employed to provide pictures with an illusion of depth, morph, or the power to alter or move as the image is viewed from different angles. Lenticular technology permits pictures to be written on the rear of a synthetic paper and laminated on the lens.

Advantages: It is an easy, low cost and fast technique.

1. It doesn't need special glass or device to browse the information, like computer or handheld reader.

Disadvantages: Information can never be modified, andmay not withstand a fire. ${ }^{21}$

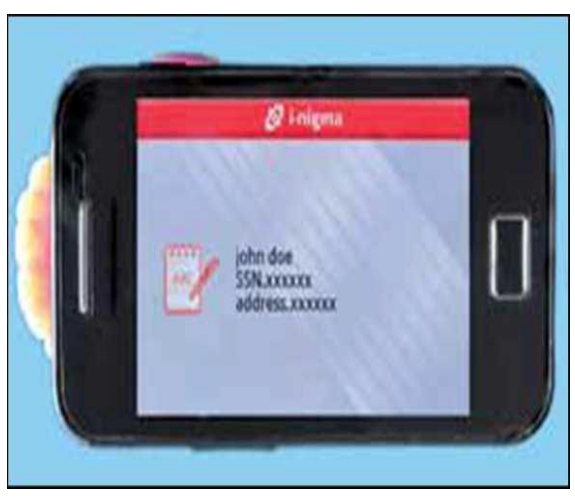

Fig. 8: Lenticular system

RFID -TAGS (Radio-frequency Identification): The RFID system consists of an information carrier, usually remarked as tag or transponder, and an electronic handheld reader. The information is kept within the chip itself, and therefore the hand-held reader can obtain all information from the chip.

Advantages: They are popular because of their small size $(8.5 \times 2.2 \mathrm{~mm})$.

1. Unlimited amount of dental plate user data can be stored in them.

Disadvantages: High price of manufacture. It isn't fireproof. ${ }^{22}$ 


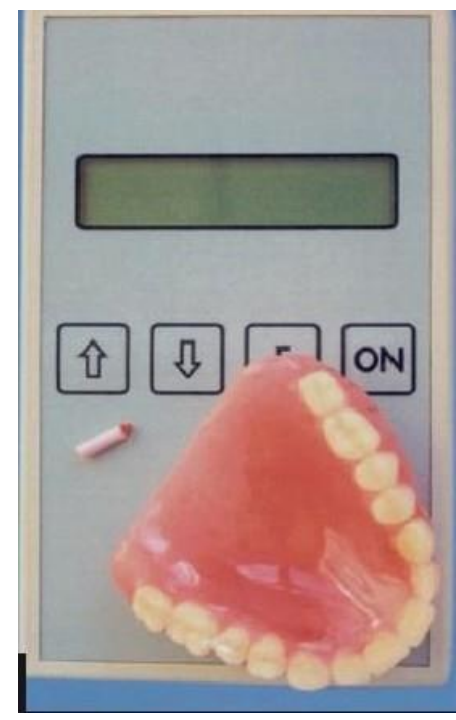

Fig. 9: RFID Tags

Aadhar Number: This method is particularly useful in India, since government has connected aadhar number digitally.

In this technique, with the help of aadhar number patient detail can be obtained.

Advantages: Patient can be located easily.

Easy and cheap to fabricate.

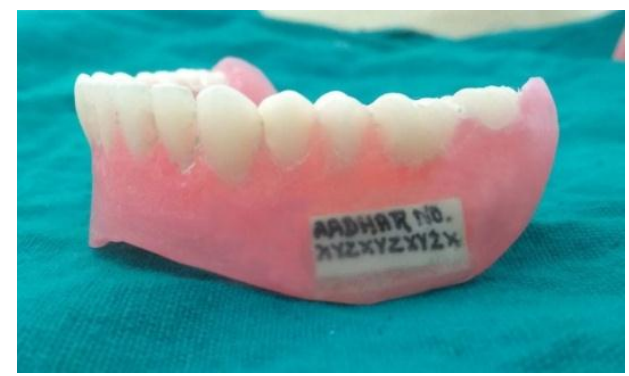

Fig. 10: Denture with aadhar number

\section{Conclusion}

In case of major disaster, the reliance on dental identification becomes more essential as teeth and restorations are the most lasting components of the human bodies. ${ }^{23-24}$ This paper reviews the varied approach of denture marking and also highlights the importance of putting identification marks on dental plate. Each technique has its own advantage and disadvantage. The key reasons for not marking dentures are cost, lack of awareness of the varied methods and a belief that it is of very little importance. Needless to say, that the worth of labeling dentures is enormous once a positive identity of an individual is desired. Hence, dental education is necessary to confirm that students, dentists and dental technician's are exposed to varied denture marking technique for providing aesthetically appropriate and efficient denture marking system that's conjointly cheap, simple and permanent.

\section{References}

1. Richmond R, Pretty IA. Identification of the edentulous individual into the accuracy of radiographic identifications. J Forensic Sci. 2010;55(4):984 -87.

2. Phulari R, Rathore RS2, Jariwala P.Journal of Clinical and Diagnostic Research. 2014 Nov, Vol-8(11): IL01.

3. Gosavi S, Gosavi S. Forensic odontology: A prosthodontic view. J Forensic Dent Sci 2012;4(1):3841.

4. Humble B. H. Identification by means of teeth. Br Dent $\mathrm{J}$ 1933:54;528.

5. Hanley H. Some Aspects of Forensic Dentistry. Proc. roy. Soc. Med. 1977:70:263-264.

6. Pretty IA. Forensic dentistry 1, Identification of human remains. Dent update 2007;34:621-2.

7. Brannon RB, Kessler HP. Problems in mass disaster dental identification a retrospective review. J Forensic Sci 1999;44:123-7.

8. Woodward JD. Denture marking for identification. J Am Dent Assoc 1979;99:59-60.

9. Pyke TF. Personal identification from artificial dentures. Aust Dent J 1970;15:495-8.

10. Haines DH. Identification in mass disasters from dental prosthesis. Int J Forensic Dent 1973;1:11-5.

11. Luthra R, Arora S, Meshram S. Denture marking for forensic identification using memory card: an innovative technique. J Indian Prosthodont Soc 2012;12(4):231-5.

12. Stavrianos C, Stavrianou I, Kafas P. Denture identification system based on Swedish guidelines: A Forensic Aspect. The Internet Journal of Forensic Science 2008;3(1).

13. Stavrianos C, Petalotis N, Metska M, Stavrianou I, Papadopoulos C. The Value of identification Marking on Dentures. Balk J Stom 2007:11;212-216.

14. DattaP, Sood S. The various methods and benefits of denture labelling. J Forensic Dent Sci. 2010;2(2):53-58.

15. Berry FA, Logan GI, Plata R, Riegel R.A post fabrication technique for identification of prosthetic devices. $J$ Prosthet Dent, 1995;73(4):341-343.

16. Ling BC, Nambiar P. Denture marking for the Malaysian population. Annal Dent Univ. Malaya 1996; 3: 43-45.

17. 17. Ling BC: Computer-printer denture microlabeling system. J Prosthet Dent,1998;79(3):363-364.

18. Misha Singla et al: Denture Marking Revisited. Int J Dent Med Res, 2014;Vol.(1):4.

19. Mona Sayed El-Gohary, Khaled Mahmoud Saad, Mohamed Maamoun El-Sheikh, Tamer Mohamed Nasr; A new denture labeling system as an antemortem record for forensic identification. Mansoura J. Forensic Med. Clin. Toxicol. 2009:XVII: 2;79-85.

20. Venkateshwaran Rajendran, Suma Karthigeyan, Surendra Manoharan, Denture marker using a two-dimensional bar code. J Prosthet Dent 2012;107:207-208.

21. Colvenkar SS. Lenticular card: A new method for denture identification. Indian J Dent Res 2010;21:112-4.

22. Millet C, Jeannin C. Incorporation of microchips to facilitate denture identification by radio-frequency tagging. J Prosthet Dent 2004;92:588-590.

23. Gladfelter IA, Smith BE. An evaluation of microdisks for dental identification. J Prosthet Dent 1989;62:352-5.

24. Fischman SL. The use of medical and dental radiographs in identification. Int Dent J 1985;35:301-6.

25. Thomas J et al. Dentures in Forensic Identification. A Review of Methods \& Benefits. J Adv Med Dent Scie2014;2(1):85-94. 